\title{
Effects of dam construction on arsenic mobility and transport in two large rivers in Tibet, China
}

SHEHONG Li ${ }^{1}$, ZHENJIE ZHAO ${ }^{1}$

${ }^{1}$ The State Key Laboratory of Environmental Geochemistry, Institute of Geochemistry, Chinese Academy of Sciences, Guiyang 550081, China. lishehong@vip.gyig.ac.cn

${ }^{2}$ The State Key Laboratory of Environmental Geochemistry, Institute of Geochemistry, Chinese Academy of Sciences, Guiyang 550081, China. Zhaozhenjie@mail.gyig.ac.cn

Construction of dams on the Singe Tsangpo (ST) and the Yarlung Tsangpo (YT) Rivers, the upper stretch of the Indus and the Brahmaputra Rivers, respectively, are expected to affect material transport. To evaluate the effects of dam construction on arsenic (As) mobility and transport in the ST River and the YT River in Tibet, water column and sediment core samples in Shiquan Reservoir of the ST and Zam Reservoir of the YT were obtained in August 2017, and January and May 2018, and additionally, at the inflows and outfalls of the reservoirs. The seasonal variation of dissolved As content in the inflow water of Zam Reservoir and Shiquan Reservoir was regulated by mixing between low-As river runoff and high-As hot spring input. The absence of surficial oxic layer can reduce the accumulation of As in surface sediments. Arsenic mobility in sediment of the two reservoirs was mainly controlled by Mn oxides and organic matter. In addition, Mn oxides was the main carrier of As in sediments. Reservoirs with long water residence time are more favorable for As retention. Sedimentation was the main mechanism of As retention. Water residence time is a key variable regulating the variation of dissolved As content in lacustrine zone and outflow water with time.

This research was funded by the National Natural Science Foundation of China (No. 41673137). 